\title{
openheart Pharmacological interventions for the prevention of contrast-induced acute kidney injury in high-risk adult patients undergoing coronary angiography: a systematic review and meta-analysis of randomised controlled trials
}

\author{
Alexander J Sharp, ${ }^{1}$ Nishith Patel, ${ }^{2}$ Barney C Reeves, ${ }^{3}$ Gianni D Angelini, ${ }^{4}$ \\ Francesca Fiorentino ${ }^{5}$
}

\begin{abstract}
- Additional material is published online only. To view please visit the journal online (http://dx.doi.org/10.1136/ openhrt-2018-000864).
\end{abstract}

To cite: Sharp AJ, Patel N Reeves BC, et al.

Pharmacological interventions for the prevention of contrastinduced acute kidney injury in high-risk adult patients undergoing coronary angiography: a systematic review and meta-analysis of randomised controlled trials. Open Heart 2019;6:e000864. doi:10.1136/

openhrt-2018-000864

Received 24 May 2018 Revised 4 October 2018 Accepted 10 November 2018

Check for updates

(c) Author(s) (or their employer(s)) 2019. Re-use permitted under CC BY-NC. No commercial re-use. See rights and permissions. Published by BMJ.

For numbered affiliations see end of article.

Correspondence to

Dr Alexander J Sharp; alexander. j.sharp@gmail.com

\section{ABSTRACT}

Objective Quantify the efficacy of strategies to prevent contrast-induced acute kidney injury (Cl-AKI) in high-risk patients undergoing coronary angiography (CAG) with or without percutaneous coronary intervention (PCl). Background $\mathrm{Cl}-\mathrm{AKI}$ remains a common problem. The renoprotective efficacy of existing pharmacological agents remains uncertain in high-risk populations.

Methods Systematic review and meta-analysis of randomised controlled trials (RCTs) to compare different strategies versus hydration in patients with chronic kidney disease (CKD) undergoing $\mathrm{CAG} \pm \mathrm{PCI}$. Primary outcome was incident $\mathrm{Cl}$-AKI. Fixed-effects meta-analyses estimated ORs, $95 \%$ Cls and heterogeneity.

Results Forty-eight RCTs were included. Seven pharmacological strategies were evaluated by multiple RCTs and 10 by one RCT each. These had varying risk of bias; $>25 \%$ of trials were at high risk of performance bias. Five strategies significantly reduced the odds of Cl-AKI: N-acetylcysteine (NAC) (27 trials, 5694 participants; $0 \mathrm{R}=0.77,95 \% \mathrm{Cl} 0.65$ to 0.91 , $\mathrm{p}=0.002, \mathrm{I}^{2}=36 \%$ ), ascorbic acid (four trials, 759 participants; $\mathrm{OR}=0.59,95 \% \mathrm{Cl} 0.39$ to $0.89, \mathrm{p}=0.01$, $\mathrm{I}^{2}=0 \%$ ), statin (two trials, 3234 participants; $\mathrm{OR}=0.59$, $95 \% \mathrm{Cl} 0.39$ to $0.89, \mathrm{p}=0.75, \mathrm{I}^{2}=0 \%$ ), trimetazidine (two trials, 214 participants; $0 \mathrm{R}=0.27,95 \% \mathrm{Cl} 0.10$ to $0.71, p=0.01, I^{2}=0 \%$ ) and nicorandil (two trials, 389 participants; $0 \mathrm{R}=0.47,95 \% \mathrm{Cl} 0.23$ to 0.94 , $\left.p=0.03, I^{2}=52 \%\right)$. Theophylline had a similar, but nonsignificant, effect. A subgroup analysis found that the benefit of NAC was highest in patients requiring a high-contrast dose.

Conclusions Several drugs are renoprotective in patients with $\mathrm{CKD}$ undergoing $\mathrm{CAG} \pm \mathrm{PCl}$. The evidence is strongest for NAC. We recommend that NAC should be used when a high dose of contrast is anticipated.

Trial registration number PROSPERO registration CRD42014014704.

Open Science Framework link: https://osf.io/vxg7d/?view_ only $=62$ bad0404b18405abd39ff2ead2575a8

\section{Key questions}

What is already known about this subject?

- Contrast-induced acute kidney injury (CI-AKI) is a common and important complication of coronary angiography (CAG). Numerous pharmacological strategies have been proposed as renoprotective. However, at present, intravenous hydration is the only universally accepted practice for those patients deemed at high risk of developing $\mathrm{Cl}-\mathrm{AKI}$.

What does this study add?

- While previous systematic reviews have assessed efficacy of multiple pharmacological strategies in a general population, we look specifically at those with established chronic kidney disease (CKD) who are at high risk of developing $\mathrm{Cl}$-AKI.

How might this impact on clinical practice?

- Several strategies were found to be renoprotective in our meta-analysis; renoprotection with $\mathrm{N}$-acetylcysteine (NAC) was most certain. Given the results of our meta-analysis, the good safety profile, availability and familiarity of healthcare professionals with NAC, we recommend its use for the prevention of $\mathrm{Cl}-\mathrm{AKI}$ in patients with CKD where high-contrast doses are anticipated.

\section{INTRODUCTION}

Contrast-induced acute kidney injury (CI-AKI) is common and an important prognostic factor in patients undergoing coronary angiography $(\mathrm{CAG})$ for diagnosis or percutaneous coronary intervention (PCI) ${ }^{12}$ It is the third most common cause of hospital-acquired AKI after the AKI induced by cardiac surgery and hypotension. ${ }^{3}$ Expansion in the use of iodinated contrast media for $\mathrm{CAG} \pm \mathrm{PCI}$, together with an ageing patient 
population, means that the incidence of CI-AKI is likely to increase.

CI-AKI is currently defined as: an increase in serum creatinine $\geq 0.3 \mathrm{mg} / \mathrm{dL}(\geq 26.5 \mu \mathrm{mol} / \mathrm{L})$ within 48 hours, or $\geq 1.5$ times the baseline value, or urine output $<0.5$ $\mathrm{mL} / \mathrm{kg} /$ hour for over six consecutive hours (kidney disease improving global outcomes [KDIGO] international guideline ${ }^{4}$ ). However, CI-AKI (or contrast-induced nephropathy) was historically defined as an increase in serum creatinine $\geq 0.5 \mathrm{mg} / \mathrm{dL}(\geq 44 \mu \mathrm{mol} / \mathrm{L})$ or $\geq 25 \%$ from baseline within 72 hours of administering contrast medium. ${ }^{5}$

The incidence of CI-AKI in low-risk patients is only $3 \%$ but can be $>30 \%$ in those at high risk of developing AKI. ${ }^{67}$ Risk factors for the development of CI-AKI include pre-existing renal impairment, diabetes mellitus, advanced age, congestive heart failure and the concurrent administration of nephrotoxic drugs. CI-AKI in these high-risk patients is associated with a need for dialysis, prolonged hospital stay, increased costs and mortality. ${ }^{8}$

Currently recommended renoprotective strategies are intravenous hydration in high-risk patients using $0.9 \%$ sodium chloride or isotonic sodium bicarbonate. ${ }^{4}$ These strategies reduce the risk of CI-AKI compared with no intervention. ${ }^{9}{ }^{10}$ The efficacy of pharmacological interventions such as N-acetylcysteine (NAC) compared with hydration alone is uncertain especially in patients at high-risk of developing CI-AKI; international guidelines recommend not using NAC for renoprotection in such patients due to a lack of evidence. ${ }^{11}$

Given the risk of CI-AKI in high-risk patients, it is important to estimate the efficacy of currently used pharmacological agents to prevent CI-AKI. Therefore, we undertook a systematic review and meta-analysis of all randomised controlled clinical trials (RCTs) of pharmacological agents to prevent CI-AKI in patients with pre-existing chronic kidney disease (CKD).

\section{METHODS}

A protocol was written in advance describing the objectives, criteria for study selection, clinical outcomes, the method for assessing risk of bias and statistical methods (online supplementary efile 1 ). The review adhered to Preferred Reporting Items for Systematic Reviews and Meta-Analyses guidelines. ${ }^{12}$

\section{Study identification}

Two investigators (AJS and FF) identified all relevant published RCTs evaluating the renoprotective effect of pharmacological agents in adult patients undergoing $\mathrm{CAG} \pm$ PCI. AJS searched Ovid MEDLINE and ClinicalTrials.gov from 1999 to 10 March 2018 using the search strategy agreed by the two authors and described in online supplementary etable 1 . This date range (18 years) was chosen to capture modern practice. Bibliographies of included studies and recent review articles were checked by AJS and FF for additional relevant articles.

\section{Study selection}

AJS and FF independently assessed trials for eligibility. Disagreements were resolved by consensus. Inclusion criteria were: (1) RCT design, AND (2) patients with CKD, AND (3) undergoing CAG \pm PCI, AND (4) control group treated by hydration with normal saline, $A N D(5)$ AKI defined as an outcome. Non-English and non-human were exclusion criteria. If there were multiple publications from an RCT, all were reviewed for data extraction and to clarify the methods or the characteristics of the population studied; the maximum reported sample size was recorded.

\section{Outcome}

The primary outcome was CI-AKI. Definitions of CI-AKI varied and were documented. If an RCT reported results for multiple CI-AKI definitions, data for the most sensitive definition (yielding the highest CI-AKI incidence) were extracted. Secondary outcomes considered were need for haemodialysis, major adverse cardiac-related events (MACEs), admission to intensive therapy units (ITU) and death.

\section{Assessment of risk of bias}

Included trials were appraised using the Cochrane risk of bias tool. ${ }^{13}$ AJS and FF assessed each outcome of interest to the review as being at low, high or unclear risk of bias in each of five domains: sequence generation; allocation concealment; blinding of participants, personnel and outcome assessors; incomplete outcome data; and selective outcome reporting.

\section{Data extraction}

Data extraction was done independently by AJS and FF and included author, year of publication, country of origin, study design, sample size, inclusion and exclusion criteria, definition of CKD and CI-AKI and study results. Discrepancies were addressed by joint re-evaluation of the original article.

\section{Statistical analysis}

Pooled ORs and 95\% CIs were estimated using fixed-effects meta-analyses. The robustness of results was investigated by comparing the results of fixed-effects and random-effects meta-analyses. We tested for and quantified heterogeneity using the $Q$ and $I^{2}$ statistics, respectively. ${ }^{14}$ Small study effects were assessed by visual inspection of funnel plots.

We conducted stratified analyses of trials evaluating NAC to investigate whether the treatment effect varied according to trial characteristics relating to eligibility criteria for the trial (diabetic status and baseline serum creatinine) and the ways in which NAC and the control treatment were administered (NAC dose and oral vs intravenous administration). For studies evaluating NAC, we also assessed the risk of small study bias by Harbord's modified test for small-study effects. All analyses were carried out using RevMan 5.3 (Copenhagen: The Nordic 
\# of records identified through database searching (Ovid MEDLINE / Embase / Cochrane) $148 / 209 / 85=442$

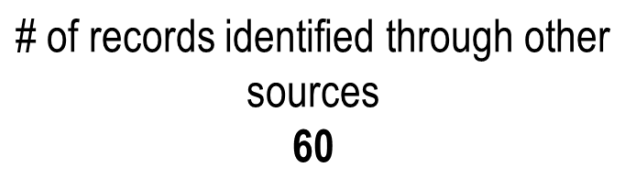

60

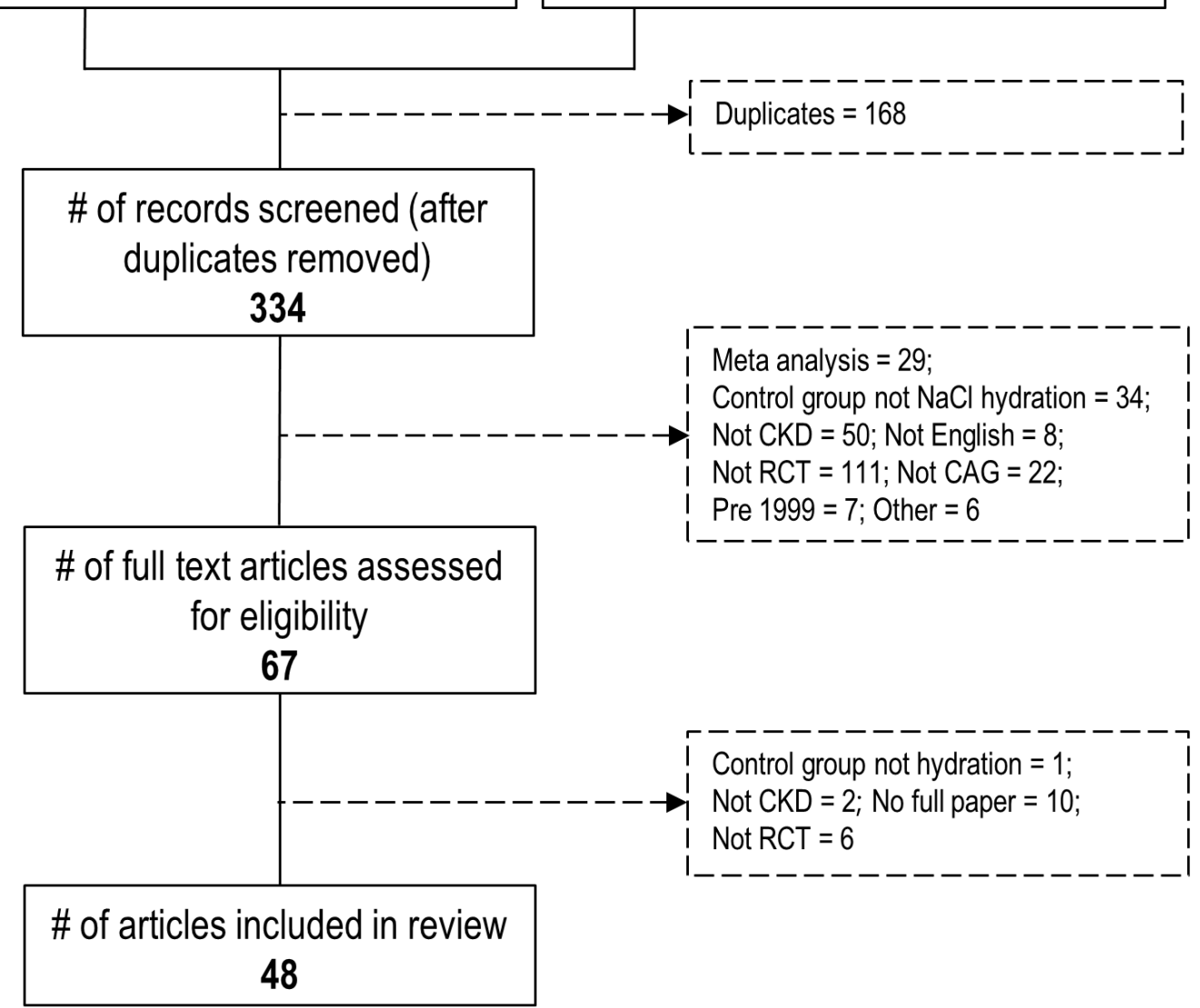

Figure 1 Flow diagram of search strategy. CAG, coronary angiography; CKD, chronic kidney disease; RCT, randomised controlled trial.

Cochrane Centre, The Cochrane Collaboration, 2014) and Stata 10.0.

\section{RESULTS}

\section{Trial characteristics}

Forty-eight eligible RCTs ${ }^{15-62}$ enrolled 14709 patients with $\mathrm{CKD}$ undergoing $\mathrm{CAG} \pm \mathrm{PCI}$. Figure 1 shows the results of the search and the number of citations at different stages of the selection process. The list of papers that were excluded and reason for exclusion is outlined in online supplementary etable 2. Seven interventions were evaluated in multiple RCTs (NAC, sodium bicarbonate, theophylline, statin, ascorbic acid, trimetazidine and nicorandil). Nine RCTs compared multiple interventions against a single control group. A further seven single interventions and three intervention combinations were evaluated by single trials: alpha-lipoic acid, anisodamine, dopamine, fenoldopam, zinc, glutathione, high-dose hydration, NAC+ascorbic acid, NAC+high dose hydration and $\mathrm{NAC}+$ theophylline. Included trials are described in online supplementary etable 3 .
RCT populations varied according to whether participants had CAG only or CAG+PCI and how CKD was defined. The definition of CI-AKI also varied (table 1); an absolute increase in serum creatinine $(\mathrm{sCr})$ of $\geq 0.5$ $\mathrm{mg} / \mathrm{dL}$ or a relative increase $\geq 25 \%$ within 48 hours was used most often (20 studies). One trial used estimated glomerular filtration rate to define CI-AKI. The dose of interventional agent administered and the route of administration also varied. CI-AKI incidence in the control groups for different definitions of CI-AKI was very variable (table 1). For the most commonly used CI-AKI definition, the median incidence of CI-AKI in the control group was $10.9 \%$ with an interquartile interval ranging from $5.9 \%$ to $14.3 \%$. Across all interventions, 26 RCTs reported incident dialysis, eight trials reported incident MACE and 13 RCTs reported death. None reported findings for intensive care unit admission.

The treatment effects for interventions evaluated in single trials were based on sample sizes $<500$ and most demonstrated no statistically significant benefit. A single-blind trial in 260 patients with diabetes evaluated 
Table 1 Definition of contrast-induced acute kidney injury (Cl-AKI) and incidence in the control group

\section{Definition of $\mathrm{Cl}-\mathrm{AKI}$}

\begin{tabular}{|c|c|c|}
\hline $\begin{array}{l}\text { Increase of } \mathrm{sCr} \geq 0.5 \mathrm{mg} / \mathrm{dL} \text { or reduction in } \mathrm{eGFR} \geq 25 \% \text { within } 48 \\
\text { hours }\end{array}$ & 1 & $13.3 \%^{21}$ \\
\hline Increase of $\mathrm{sCr} \geq 0.5 \mathrm{mg} / \mathrm{dL}$ or increase $\mathrm{sCr} \geq 25 \%$ within 48 hours & 20 & $\begin{array}{l}0 \%,{ }^{39} 2.7 \%,{ }^{33} 3.4 \%,{ }^{44} 5 \%,{ }^{30} 5.4 \%,{ }^{42} 6.3 \%,{ }^{36} 6.4 \%,{ }^{28} 6.6 \%,{ }^{46} 6.9 \%,{ }^{47} \\
10.0 \%,{ }^{57} 11.8 \%,{ }^{54} 13 \%,{ }^{34} 13.6 \%,{ }^{55} 14 \%,{ }^{46} 14.3 \%,{ }^{15} 14.3 \%,{ }^{56} 16.6 \%, \\
23.8 \%,{ }^{18} 25 \%,{ }^{27} 44.8 \%{ }^{19}{ }^{4}\end{array}$ \\
\hline Increase of $\mathrm{sCr} \geq 0.5 \mathrm{mg} / \mathrm{dL}$ or increase $\mathrm{sCr} \geq 25 \%$ within 72 hours & 4 & $3.9 \%,{ }^{45} 12.5 \%,{ }^{35} 20.3 \%,{ }^{52} 20 \%,{ }^{59} 17.5 \%{ }^{61}$ \\
\hline $\begin{array}{l}\text { Increase of } \mathrm{sCr} \geq 0.5 \mathrm{mg} / \mathrm{dL} \text { or increase } \mathrm{sCr} \geq 25 \% \text { within } 120 \\
\text { hours }\end{array}$ & 2 & $14 \%,{ }^{50} 20 \%,{ }^{41} 8.4 \%{ }^{62}$ \\
\hline $\begin{array}{l}\text { Increase of } \mathrm{sCr} \geq 0.5 \mathrm{mg} / \mathrm{dL} \text { or increase } \mathrm{sCr} \geq 25 \% \text { within } 192 \\
\text { hours }\end{array}$ & 1 & $20.7 \%^{32}$ \\
\hline Increase of $\mathrm{sCr} \geq 0.5 \mathrm{mg} / \mathrm{dL}$ or increase $\mathrm{sCr} \geq 25 \%$ no timeframe. & 1 & $16 \%{ }^{60}$ \\
\hline Increase of $\mathrm{sCr} \geq 0.5 \mathrm{mg} / \mathrm{dL}$ within 24 hours & 1 & $5.8 \%{ }^{29}$ \\
\hline Increase of $\mathrm{sCr} \geq 0.5 \mathrm{mg} / \mathrm{dL}$ within 48 hours & 9 & $6.0 \%,{ }^{37} 6.9 \%,{ }^{53} 8 \%,{ }^{22} 8 \%,{ }^{23} 12 \%-15.3 \%,{ }^{48} 20 \%,{ }^{38} 22.0 \%,{ }^{20} 24.6 \%{ }^{31}$ \\
\hline Increase $\mathrm{sCr} \geq 25 \%$ within 96 hours & 2 & $7.3 \%,{ }^{40} 21 \%,{ }^{17}$ \\
\hline Increase $\mathrm{sCr} \geq 25 \%$ no timeframe & 1 & $30 \%{ }^{51}$ \\
\hline Increase of $\mathrm{sCr} \geq 44.2 \mu \mathrm{mol} / \mathrm{L}$ within 48 hours & 1 & $10.1 \%^{58}$ \\
\hline
\end{tabular}

eGFR, estimated glomerular filtration rate; sCr, serum creatinine.

anisodamine versus hydration with saline and showed a statistically significant reduction in the incidence of CI-AKI; OR for CI-AKI=0.43, 95\% CI 0.21 to 0.88, $\mathrm{p}=0.02$. Three trials of theophylline, two trials of trimetazidine and two trials of nicorandil also randomised $<500$ patients. However, the trials of trimetazidine and nicorandil did show a statistically significant reduction in incidence of CI-AKI (trimetazidine OR for CI-AKI=0.27, 95\% CI 0.10 to $0.71, \mathrm{p}=0.01$; nicorandil OR for CI-AKI $0.47,95 \%$ CI 0.23 to $0.94, \mathrm{p}=0.03)$. The findings for these interventions are not considered further because of the low power of these RCTs.

\section{Risk of bias}

Figure 2 shows the risk of bias assessment for all RCTs. Approximately $50 \%$ of RCTs were judged to be at an

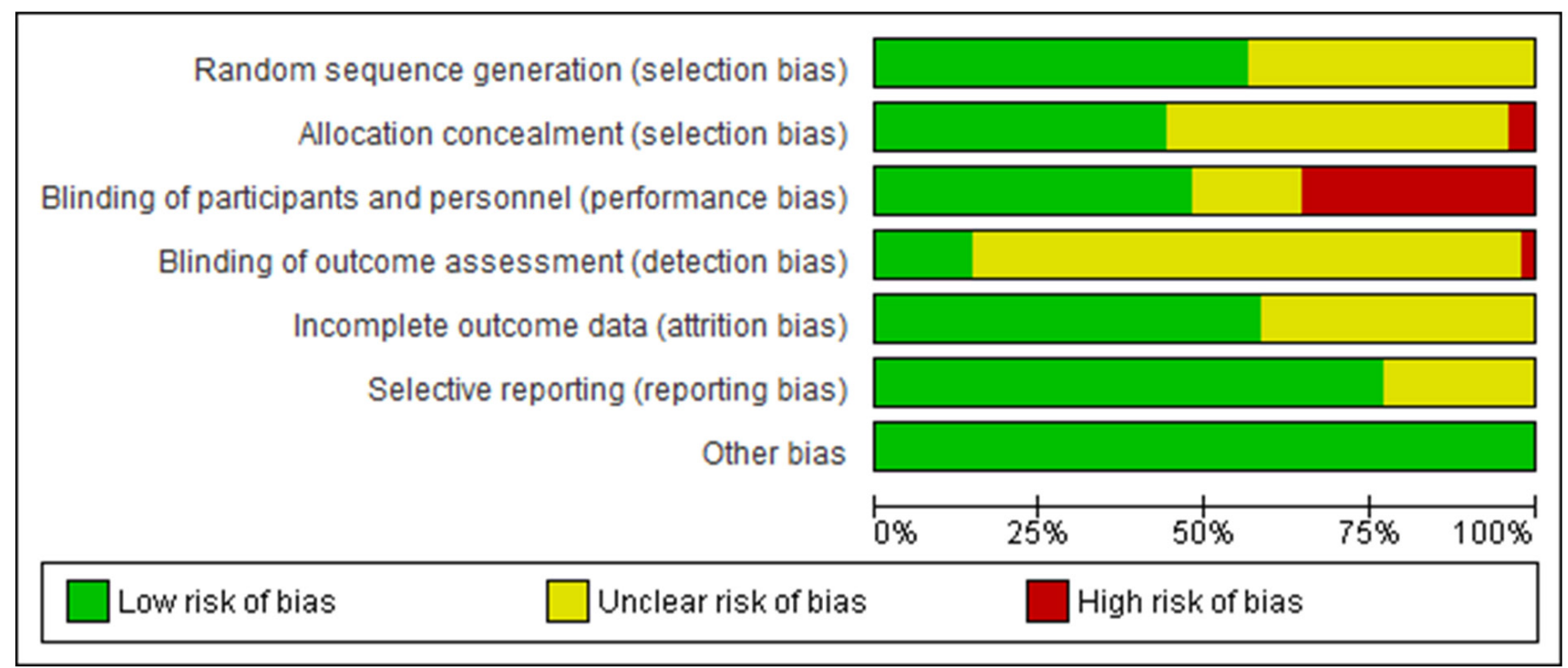

Figure 2 Methodological quality graph - authors' judgement on risk of bias associated with each methodological quality item presented as a percentage across all included studies. 
unclear risk of bias with respect to random sequence generation and allocation concealment due to inadequate reporting. Several RCTs were at high risk of performance bias; $>25 \%$ failed to blind participants and personnel. The majority did not clearly report that outcome assessors were blinded and $40 \%$ had inadequate or unclear documentation of patients lost to follow-up.

Seven registered RCTs were identified through our search strategy that are not included in the metanalysis. Three were terminated before completion: one because the patient pathway became infeasible due to pressure for short hospital stays (NCT01786824); one because the drug became unavailable (NCT01071993); and one because it was not reaching its recruitment goal (NCT00494637). Data for these RCTs were not available. Three other RCTs (NCT01690832, NCT00424320 and NCT01871792) were described as status 'unknown'; a PubMed search for the lead investigator did not identify any relevant publication of RCT results. One trial (NCT00531765) investigating sodium bicarbonate compared with saline appeared to have been completed in May 2010 but no publication of the results was found.

The funnel plots in esupplement online supplementary efigures 1-5 show graphs for all studies (all interventions) and for NAC studies only. The distribution of the studies appears balanced suggesting a low risk of small study bias.

\section{$\mathrm{N}$-acetylcysteine}

Twenty-seven trials $(\mathrm{n}=5694$; sample sizes ranged from 14 to 2482) assessed NAC with hydration compared with saline hydration alone with respect to the risk of CI-AKI (online supplementary etable 3 ). The NAC dose varied between $500 \mathrm{mg}$ and $12000 \mathrm{mg}$. Three trials administered NAC intravenously and 24 trials administered NAC orally. Eleven trials used $0.45 \%$ hydration and 16 used $0.90 \%$ hydration. Most trials identified incident CI-AKI for up to 48 hours after the intervention but seven did so for longer. Overall, using a fixed-effects analysis, NAC resulted in a $23 \%$ reduction in the odds of CI-AKI (OR $=0.77,95 \%$ CI 0.65 to $0.91, \mathrm{p}=0.002)$ with modest between-trial heterogeneity $\left(\mathrm{I}^{2}=36 \%\right)$ (figure 3 ) and no evidence of bias due to small study effects (Harbord's modified test for small study effects $\mathrm{p}=0.103$; funnel plot (online supplementary efigure 5) ). Results of a random-effects analysis were similar $(\mathrm{OR}=0.70,95 \%$ CI 0.54 to $0.92, \mathrm{p}=0.01)$.

\section{Bicarbonate}

Nine trials ( $\mathrm{n}=3766$; sample sizes ranged from 72 to 2498) evaluated hydration with sodium bicarbonate compared with normal saline. Sodium bicarbonate was infused in all but one trial; doses ranged from $12 \mathrm{~mL} / \mathrm{kg}$ of $154 \mathrm{mEq} / \mathrm{L}$ to $1.5 \mathrm{~mL} / \mathrm{kg}$ of $154 \mathrm{mEq} / \mathrm{L}$ sodium bicarbonate. Using a fixed-effects analysis, hydration with bicarbonate did not significantly reduce the odds of CI-AKI (OR=0.89, 95\% CI 0.71 to $1.12, \mathrm{p}=0.31)$ with some evidence of heterogeneity $\left(\mathrm{I}^{2}=46 \%\right)$ (figure 3$)$. Results of a random-effects analysis showed a similar trend $(\mathrm{OR}=0.72,95 \%$ CI 0.45 to $1.15, \mathrm{p}=0.17)$.

\section{Ascorbic acid}

Four trials ( $\mathrm{n}=759$; sample sizes ranged from 81 to 231) evaluated ascorbic acid compared with normal saline. Doses ranged from $7 \mathrm{~g}$ oral to $500 \mathrm{mg}$ intravenously. One trial investigated the occurrence of CI-AKI up to 120 hours following the intervention. Overall, using a fixed-effects analysis, ascorbic acid resulted in a $41 \%$ reduction in the odds of developing CI-AKI ( $\mathrm{OR}=0.59,95 \%$ CI 0.39 to $0.89, \mathrm{p}=0.01)$ with no heterogeneity $\left(\mathrm{I}^{2}=0 \%\right)$ (figure 3 ). Results of a random-effects analysis were identical.

\section{Statin}

Two trials $(\mathrm{n}=3234)$ evaluated statin compared with hydration with normal saline, with doses of $160 \mathrm{mg}$ of simvastatin $(\mathrm{n}=236)$ and $50 \mathrm{mg}$ rosuvastatin $(\mathrm{n}=2998)$. Overall, using a fixed-effects analysis, statin resulted in a $41 \%$ reduction in odds of developing CI-AKI (OR $=0.59$, $95 \%$ CI 0.39 to $0.89, \mathrm{p}=0.75$ ) (figure 3 ). Results of a random-effects analysis were identical.

\section{Secondary outcomes}

The prespecified secondary outcomes were not reported across the majority of trials. Therefore, analyses were underpowered to detect a clinically important effect.

Pooled estimates for need for dialysis showed no significant reductions with NAC ( 15 RCTs, $n=4277$, OR=0.95, $95 \%$ CI 0.52 to 1.76 ), bicarbonate ( 7 RCTs, $n=3522$, $\mathrm{OR}=0.99,95 \%$ CI 0.51 to 1.93 ) or statins ( 2 RCTs, 1745 pts, OR $=0.33,95 \%$ CI 0.01 to 8.13 ) compared with saline hydration. Nevertheless, all effect estimates were consistent with the benefits shown for CI-AKI (online supplementary efigure 2).

The pooled estimate effect of NAC compared with saline hydration on MACE showed no significant reduction in risk ( 4 RCTs, $\mathrm{n}=3007$ patients, $\mathrm{OR}=1.16$, 95\% CI 0.90 to 1.50; online supplementary efigure 3 ). Most trials did not report MACE. Pooled estimates for mortality were similarly imprecise for NAC ( 8 RCTs, $\mathrm{n}=3808$, OR=1.29, 95\% CI 0.87 to 1.91) and bicarbonate ( 3 RCTs, $n=2943, \mathrm{OR}=1.21,95 \%$ CI 0.76 to 1.93 ; Online supplementary efigure 4 ).

\section{Stratified analyses}

Analyses of RCTs evaluating NAC, by diabetic status, type of intervention, contrast dose, baseline serum creatinine, NAC dose, route of administration, date of publication and risk of bias, are summarised in table 2. Studies were considered at low risk of bias if they demonstrated allocation concealment and either blinding of participants and personnel or outcome assessment.

The benefit of NAC in preventing CI-AKI appeared to be greater in trials where a larger average volume of contrast was used (average contrast volume $>125 \mathrm{~mL}$, $\mathrm{OR}=0.45,95 \%$ CI 0.32 to $0.64, \mathrm{I}^{2}=28 \%$ vs average contrast volume $<125 \mathrm{~mL}$ OR $=0.89,95 \%$ CI 0.74 to $1.08, \mathrm{I}^{2}=13 \%$ ). All trials used either low or iso-osmolar contrast. The benefit of NAC was also more evident in trials recruiting 


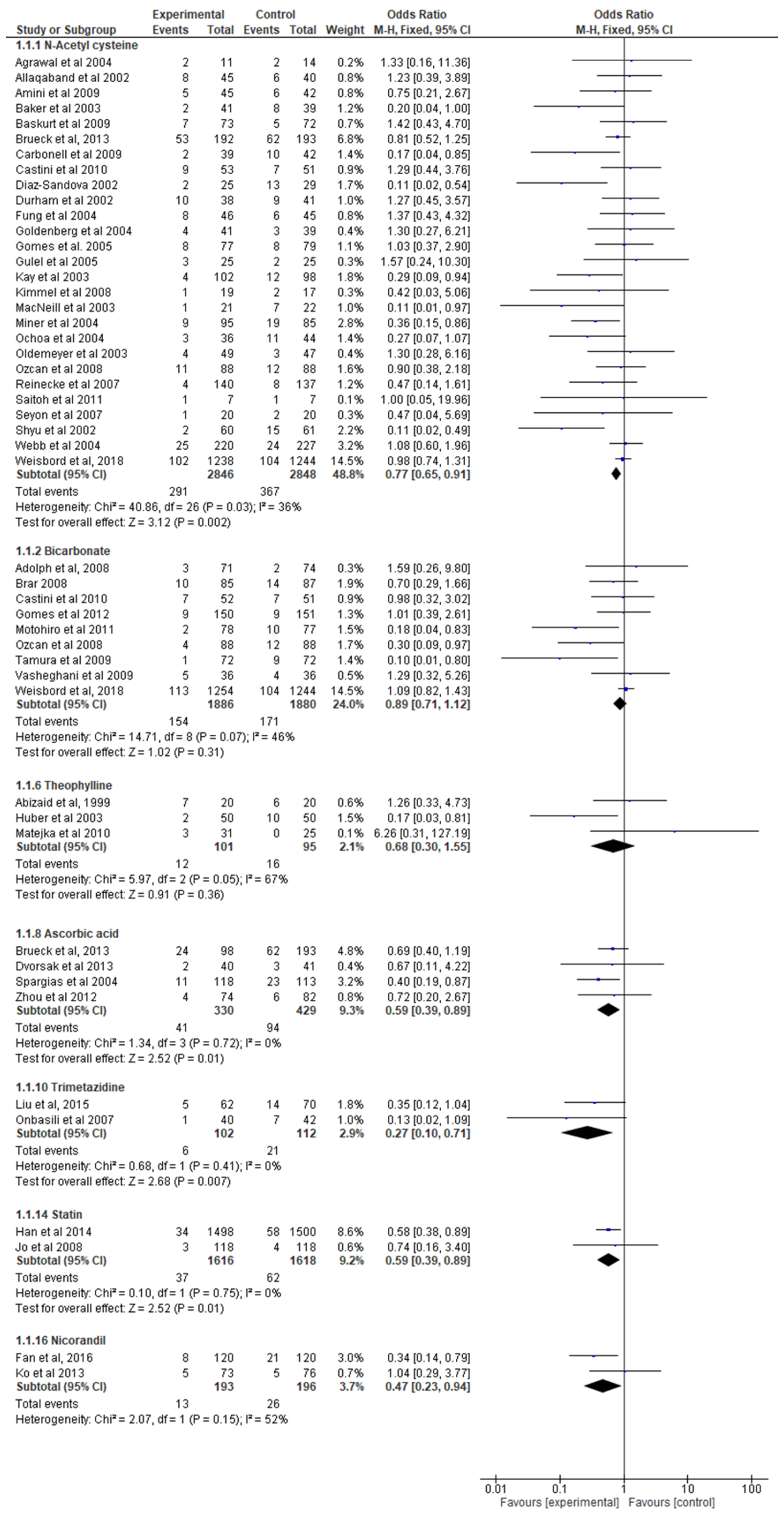

Figure 3 Forest plot of drugs (experimental) versus hydration with saline (control) in incidence of contrast-induced acute kidney injury. 


\begin{tabular}{|c|c|c|c|c|c|}
\hline Characteristic & Stratum & $\mathrm{N} / \mathrm{n}$ & OR & $95 \% \mathrm{Cl}$ & $I^{2}$ \\
\hline \multirow[t]{2}{*}{ Diabetic status } & Diabetic & $1 / 87$ & 0.75 & 0.21 to 2.67 & $\mathrm{n} / \mathrm{a}$ \\
\hline & Non-diabetic & $26 / 5607$ & 0.77 & 0.65 to 0.91 & 39 \\
\hline \multirow[t]{2}{*}{ Intervention } & CAG & $14 / 3996$ & 0.80 & 0.65 to 0.99 & 50 \\
\hline & $\mathrm{CAG} / \mathrm{PCl}$ & $13 / 1698$ & 0.72 & 0.55 to 0.93 & 16 \\
\hline \multirow[t]{2}{*}{ Contrast dose* } & $<125 \mathrm{~mL}$ & $13 / 4300$ & 0.89 & 0.74 to 1.08 & 13 \\
\hline & $>125 \mathrm{~mL}$ & $13 / 1344$ & 0.45 & 0.32 to 0.64 & 28 \\
\hline \multirow[t]{2}{*}{ Renal function* } & $\mathrm{sCr} \geq 1.1$ & $11 / 1640$ & 0.76 & 0.57 to 1.02 & 0 \\
\hline & $\mathrm{sCr} \geq 1.4$ & $13 / 980$ & 0.46 & 0.32 to 0.65 & 46 \\
\hline \multirow[t]{3}{*}{ NAC dose* } & $<2400 \mathrm{mg}$ & $6 / 1214$ & 0.74 & 0.54 to 1.00 & 53 \\
\hline & $=2400 \mathrm{mg}$ & $13 / 1349$ & 0.69 & 0.49 to 0.98 & 32 \\
\hline & $>2400 \mathrm{mg}$ & $7 / 3071$ & 0.87 & 0.68 to 1.11 & 31 \\
\hline \multirow[t]{2}{*}{ NAC route } & Oral & $23 / 4701$ & 0.77 & 0.64 to 0.94 & 34 \\
\hline & Intravenous & $4 / 993$ & 0.75 & 0.54 to 1.04 & 60 \\
\hline \multirow[t]{2}{*}{ Date } & 1999-2008 & $20 / 2396$ & 0.62 & 0.48 to 0.80 & 41 \\
\hline & 2009-present & $7 / 3298$ & 0.92 & 0.73 to 1.13 & 0 \\
\hline \multirow[t]{2}{*}{ Risk of bias } & Low risk & $10 / 3975$ & 0.82 & 0.67 to 1.00 & 52 \\
\hline & High risk & $17 / 1719$ & 0.67 & 0.49 to 0.90 & 26 \\
\hline
\end{tabular}

${ }^{*}$ The sum of the trials across strata for contrast dose do not sum 27 because one trial did not report average contrast dose. Likewise for renal function, three trials did not describe baseline $\mathrm{sCr}$ adequately and were excluded. Likewise for NAC, dose one trial based dose on patient weight and was excluded.

CAG, coronary angiography; N, number of trials; $\mathrm{PCl}$, percutaneous coronary intervention; $\mathrm{n}$, total number of participants; sCr, serum creatinine.

patients with severe CKD (baseline $\mathrm{sCr} \geq 1.4 \mathrm{mg} / \mathrm{dL}$; $\mathrm{OR}=0.46,95 \%$ CI 0.32 to $0.65, \mathrm{I}^{2}=46 \%$ ) compared with less severe or moderately severe CKD (baseline $\mathrm{sCr} \geq 1.1$ $\mathrm{mg} / \mathrm{dL}$; OR $0.76,95 \%$ CI 0.57 to $1.02, \mathrm{I}^{2}=0 \%$; interaction $\left.\mathrm{chi}^{2}=4.61, \mathrm{df}=1, \mathrm{p}=0.032\right)$. The benefit of NAC was not evident in trials conducted after 2009 (before 2009, $\mathrm{OR}=0.62$ (95\% CI 0.48 to 0.80$)$; after $2009 \mathrm{OR}=0.92(95 \%$ CI 0.73 to 1.13$)$ ).

\section{DISCUSSION}

\section{Main findings}

Our review has three main findings. First, several agents significantly reduce the incidence of CI-AKI in high-risk patients undergoing $\mathrm{CAG} \pm \mathrm{PCI}$. The evidence is most certain for NAC; efficacy was estimated with excellent precision (27 RCTs recruiting $>5000$ patients) with only moderate heterogeneity $\left(\mathrm{I}^{2}=36 \%\right)$. Second, the benefit of NAC is most evident in those receiving higher contrast doses ( $>125 \mathrm{~mL}$ of iso or low osmolar contrast). Finally, NAC appears to have greater efficacy in patients with more severe CKD. The benefits of other agents found to be significantly renoprotective were larger, ranging from $\mathrm{OR}=0.27$ (trimetadzine) to 0.59 (statin and ascorbic acid) but were estimated less precisely, since they were based on few trials (2-4) or included fewer participants (214-3234).

\section{Strengths and limitations}

We conducted the review according to a prespecified protocol, used a comprehensive search strategy, assessed the risk of bias in trials using a recommended tool and explored a range of trial characteristics that might explain heterogeneity of trial estimates.

It could be argued that the overall effect of NAC might arise from an epoch effect, that is, only be apparent in earlier trials, particularly in the light of the results of the prevention of serious adverse events following angiography (PRESERVE) trial. ${ }^{62}$ This international multicentre factorial trial is the only trial to have reported in the last 5 years. It randomised over 5000 patients at high risk for CI-AKI to receive intravenous bicarb or $0.9 \%$ saline and oral NAC or placebo. The trial was stopped early due to absence of effect after $67 \%$ of the target recruitment was completed. The PRESERVE trial contributes $30 \%$ of the total weight in the NAC meta-analysis and inevitably dominates the estimate for trials reporting after 2009.

We carried out additional subgroup analyses, varying the cutpoint for classifying included RCTs into older and more recent subgroups; we compared effect estimates for older and more recent subgroups and inspected the risk of bias of included trials as a function of time (see online supplementary etable 4 and online supplementary efigure 6). These analyses show that: (A) the stratum specific estimates are stable over the period since 2004; (B) there is no evidence that older RCTs had a higher risk of bias; and $(\mathrm{C})$ the treatment effect was larger for earlier studies than later studies.

We argue that a change in practice between time periods is the likeliest explanation (given that more recent trials 
were not, on average, 'better'). For example, improved techniques leading to a lower dose of contrast being required (online supplementary etable 5 details trial date arranged by average contrast dose used). However, NAC remains a sensible and potentially beneficial intervention in cases where greater doses of contrast are likely to be required, for example, in patients with known difficult access or chronic total occlusion procedures.

There are some other limitations. RCTs varied in their eligibility criteria, notably the severity of CKD that qualified patients as eligible, definitions of CI-AKI used, dose and route of administration of the drug being evaluated. We investigated the effects of RCT characteristics for RCTs of NAC but, except for the comparison patients with severe versus moderately severe and severe CKD, these analyses had low power. They were also potentially confounded by other RCT characteristics, for example, country or dates when the trial was conducted.

We had not prespecified any hypothesis about modification of the relative treatment effect by the severity of CI-AKI events. Although RCTs used different CI-AKI definitions, we did not carry out a subgroup analysis by CI-AKI severity to quantify the interaction because of the diversity of definitions (table 1). Future RCTs will likely use a consistent CI-AKI definition. ${ }^{4}$

Some trials compared multiple interventions against a common control group. However, multiple estimates from a single trial were never included in the same meta-analyses, avoiding the need to take into account the dependency between two or more estimates. We identified seven trials for which we were unable to find any data, which could have caused publication bias.

Cochrane recommends that review authors should not include search terms describing relevant outcomes because this may lead review authors to overlook trials that are at risk of selective outcome reporting. ${ }^{63}$ We believe we avoided this risk, despite specifying CI-AKI in the search strategy, because of the specific nature of the research question; it is hard to conceive of an RCT designed to evaluate an intervention to reduce incident CI-AKI not subsequently reporting this effect.

\section{Findings in relation to existing literature}

Current guidelines recommend several strategies to prevent CI-AKI. ${ }^{4}$ Non-pharmacological strategies include using the lowest possible dose of contrast medium and using iso-osmolar or low-osmolar iodinated contrast medium in patients at risk of CI-AKI. The main pharmacological intervention is intravenous volume expansion with isotonic sodium chloride in patients at high-risk of CI-AKI. ${ }^{4}$ Current guidelines do not agree about the use of NAC for renoprotection. The international KDIGO guidelines recommend using oral NAC together with intravenous isotonic crystalloids for the prevention of CI-AKI. ${ }^{4}$ However, this recommendation is graded as level $2 \mathrm{D}$, indicating that the supporting evidence is considered very low quality. The recent UK guidelines recommend against using NAC as there is no convincing evidence. ${ }^{64}$
The current uncertainty about the use of NAC arises from 11 recently published systematic reviews. ${ }^{65-76}$ Seven of these reviews found NAC to be renoprotective. However, marked heterogeneity and the risk of publication bias caused their authors to question the validity of these findings. The heterogeneity of effect observed in the reviews may have arisen because the reviews included RCTs that recruited both low-risk and high-risk patients. Our meta-analysis of solely high-risk patients demonstrated only modest heterogeneity. Even among the highrisk patients that were the focus of this review, we found evidence that the benefit of NAC is greatest in patients with severe CKD.

Two systematic reviews published over 10 years ago restricted their analyses to patients with baseline CKD. ${ }^{77}$ Both reviews found a renoprotective effect of NAC in patients with pre-existing CKD undergoing procedures requiring intravenous radiocontrast medium. However, they examined heterogenous populations with participants in included studies undergoing CT or CAG.

The beneficial effects of NAC, sodium bicarbonate, ascorbic acid and statin are scientifically plausible. Generation of reactive oxygen species is central to the pathophysiology of CI-AKI. ${ }^{79}$ Patients with CKD have defective antioxidant systems and increased oxidative stress associated with inflammation and endothelial dysfunction. ${ }^{80} 81$ Administration of antioxidants such as NAC would, therefore, be expected to replenish antioxidant stores and remove oxygen free radicals, reducing contrast induced inflammation and renal cell death.

We recommend using NAC for the prevention of CI-AKI in patients with CKD who are expected to require high doses of contrast. We recommend NAC rather than another agent for the following reasons: (1) the effect estimate has good precision and is derived from many studies, (2) NAC is cheap and easily available, (3) has a good safety profile and (4) health professionals are familiar in its administration. We recommend using a NAC dose of $2400 \mathrm{mg}$ as this was found efficacious in the largest number of trials and had only minor heterogeneity. Both intravenous and oral routes of administration were equally effective and we therefore recommend that the route of administration be tailored to the clinical scenario.

\section{CONCLUSION}

In conclusion, we have demonstrated that NAC, sodium bicarbonate, ascorbic acid and statins are renoprotective in patients with CKD undergoing CAG/PCI. Evidence is strongest for NAC in patients requiring high-contrast doses. The trials we included in our review tended to be small and most were at risk of bias in at least one domain. Nevertheless, the magnitude, consistency and precision of the observed effect is unlikely to be explained by bias. We recommend that guidelines concerning CI-AKI be amended to reflect this evidence. 
Author affiliations

${ }^{1}$ Addenbrookes Hospital, Cambridge, UK

${ }^{2}$ Royal Papworth Hospital, Cambridge, UK

${ }^{3}$ Bristol Heart Institute, University of Bristol, Bristol Royal Infirmary, Bristol, UK

${ }^{4}$ National Heart \& Lung Institute, Imperial College London, London, UK

${ }^{5}$ Imperial College Trial Unit and Division of Surgery and Cancer, Imperial College

London, St. Mary's Hospital, London, UK

Contributors AJS carried out the review under the supervision of FF and NP. NP contributed expertise about kidney dysfunction and coronary disease, advised about aspects of the meta-analysis and drafted the manuscript with FF. BCR conceived the research question, advised about aspects of the meta-analysis and the presentation of the findings of the review. GDA conceived the research question and advised on the clinical interpretation of the data. FF conceived the research question, supervised the conduct of the study, supervised AS, checked the study selection and data extraction and drafted the manuscript with NP. All authors revised the manuscript for important intellectual content and read and approved the final version.

Funding BCR's contribution to this review was funded by the Bristol Biomedical Research Centre (Cardiovascular Theme). GDA holds a British Heart Foundation personal chair (CH/92027/7163). FF's contribution to this review was funded by the British Heart Foundation.

Competing interests None declared.

Patient consent for publication Not required.

Provenance and peer review Not commissioned; externally peer reviewed.

Data sharing statement FF had full access to all the data in the study and takes responsibility for the integrity of the data and the accuracy of the data analysis.

Open access This is an open access article distributed in accordance with the Creative Commons Attribution Non Commercial (CC BY-NC 4.0) license, which permits others to distribute, remix, adapt, build upon this work non-commercially, and license their derivative works on different terms, provided the original work is properly cited, appropriate credit is given, any changes made indicated, and the use is non-commercial. See: http://creativecommons.org/licenses/by-nc/4.0

\section{REFERENCES}

1. Tsai TT, Patel UD, Chang TI, et al. Contemporary incidence, predictors, and outcomes of acute kidney injury in patients undergoing percutaneous coronary interventions: insights from the NCDR Cath-PCI registry. JACC Cardiovasc Interv 2014;7:1-9.

2. Crimi G, Leonardi S, Costa F, et al. Incidence, prognostic impact, and optimal definition of contrast-induced acute kidney injury in consecutive patients with stable or unstable coronary artery disease undergoing percutaneous coronary intervention. insights from the allcomer PRODIGY trial. Catheter Cardiovasc Interv 2015;86:E19-E27.

3. McCullough PA. Contrast-induced acute kidney injury. J Am Coll Cardiol 2008;51:1419-28.

4. KDIGOKAKIW. KDIGO Clinical Practice Guideline for Acute Kidney Injury. Kidney Int 2012;(Suppl 2):1-138.

5. McCullough PA, Adam A, Becker CR, et al. Epidemiology and prognostic implications of contrast-induced nephropathy. Am J Cardiol 2006;98(6):5-13.

6. Rihal CS, Textor SC, Grill DE, et al. Incidence and prognostic importance of acute renal failure after percutaneous coronary intervention. Circulation 2002;105:2259-64.

7. Gruberg L, Mintz GS, Mehran R, et al. The prognostic implications of further renal function deterioration within $48 \mathrm{~h}$ of interventional coronary procedures in patients with pre-existent chronic renal insufficiency. J Am Coll Cardiol 2000;36:1542-8.

8. Jorgensen AL. Contrast-induced nephropathy: pathophysiology and preventive strategies. Crit Care Nurse 2013;33:37-46.

9. Zoungas S, Ninomiya T, Huxley R, et al. Systematic review: sodium bicarbonate treatment regimens for the prevention of contrastinduced nephropathy. Ann Intern Med 2009;151:631-8.

10. Solomon R, Werner C, Mann D, et al. Effects of saline, mannitol, and furosemide on acute decreases in renal function induced by radiocontrast agents. N Engl J Med 1994;331:1416-20.

11. Authors/Task Force members, Windecker S, Kolh P, et al. 2014 ESC/EACTS Guidelines on myocardial revascularization: The Task Force on Myocardial Revascularization of the European Society of Cardiology (ESC) and the European Association for Cardio-Thoracic Surgery (EACTS)Developed with the special contribution of the
European Association of Percutaneous Cardiovascular Interventions (EAPCI). Eur Heart J 2014;35:2541-619.

12. Liberati A, Altman DG, Tetzlaff J, et al. The PRISMA statement for reporting systematic reviews and meta-analyses of studies that evaluate healthcare interventions: explanation and elaboration. BMJ 2009;339:b2700.

13. Higgins JP, Altman DG, Gøtzsche PC, et al. The Cochrane Collaboration's tool for assessing risk of bias in randomised trials. BMJ 2011;343:d5928.

14. Higgins JP, Thompson SG. Quantifying heterogeneity in a metaanalysis. Stat Med 2002;21:1539-58

15. Amini M, Salarifar M, Amirbaigloo A, et al. N-acetylcysteine does not prevent contrast-induced nephropathy after cardiac catheterization in patients with diabetes mellitus and chronic kidney disease: a randomized clinical trial. Trials 2009;10:45.

16. Agrawal M, Wodlinger AM, Huggins CE, et al. Effect of $\mathrm{N}$-Acetylcysteine on Serum Creatinine Concentration in Patients with Chronic Renal Insufficiency Who Are Undergoing Coronary Angiography. Heartdrug 2004;4:87-91.

17. Baker CS, Wragg A, Kumar S, et al. A rapid protocol for the prevention of contrast-induced renal dysfunction: the RAPPID study. J Am Coll Cardiol 2003;41:2114-8.

18. Carbonell N, Sanjuán R, Blasco M, et al. N-acetylcysteine: shortterm clinical benefits after coronary angiography in high-risk rena patients. Rev Esp Cardiol 2010;63:12-19.

19. Diaz-Sandoval LJ, Kosowsky BD, Losordo DW. Acetylcysteine to prevent angiography-related renal tissue injury (the APART trial). Am J Cardiol 2002;89:356-8.

20. Durham JD, Caputo C, Dokko J, et al. A randomized controlled trial of $\mathrm{N}$-acetylcysteine to prevent contrast nephropathy in cardiac angiography. Kidney Int 2002;62:2202-7.

21. Fung JW, Szeto CC, Chan WW, et al. Effect of N-acetylcysteine for prevention of contrast nephropathy in patients with moderate to severe renal insufficiency: a randomized trial. Am J Kidney Dis 2004;43:801-8.

22. Goldenberg I, Shechter M, Matetzky S, et al. Oral acetylcysteine as an adjunct to saline hydration for the prevention of contrast-induced nephropathy following coronary angiography. A randomized controlled trial and review of the current literature. Eur Heart J 2004;25:212-8.

23. Gulel O, Keles T, Eraslan $\mathrm{H}$, et al. Prophylactic acetylcysteine usage for prevention of contrast nephropathy after coronary angiography. $J$ Cardiovasc Pharmacol 2005;46:464-7.

24. Kay J, Chow WH, Chan TM, et al. Acetylcysteine for prevention of acute deterioration of renal function following elective coronary angiography and intervention: a randomized controlled trial. JAMA 2003;289:553-8.

25. MacNeill BD, Harding SA, Bazari $\mathrm{H}$, et al. Prophylaxis of contrastinduced nephropathy in patients undergoing coronary angiography. Catheter Cardiovasc Interv 2003;60:458-61.

26. Miner SE, Dzavik V, Nguyen-Ho P, et al. N-acetylcysteine reduces contrast-associated nephropathy but not clinical events during longterm follow-up. Am Heart J 2004;148:690-5

27. Ochoa A, Pellizzon G, Addala S, et al. Abbreviated dosing of $\mathrm{N}$-acetylcysteine prevents contrast-induced nephropathy after elective and urgent coronary angiography and intervention. J Interv Cardiol 2004;17:159-65.

28. Oldemeyer JB, Biddle WP, Wurdeman RL, et al. Acetylcysteine in the prevention of contrast-induced nephropathy after coronary angiography. Am Heart J 2003;146:1089-94.

29. Reinecke H, Fobker M, Wellmann J, et al. A randomized controlled trial comparing hydration therapy to additional hemodialysis or $\mathrm{N}$-acetylcysteine for the prevention of contrast medium-induced nephropathy: the Dialysis-versus-Diuresis (DVD) Trial. Clin Res Cardiol 2007;96:130-9.

30. Seyon RA, Jensen LA, Ferguson IA, et al. Efficacy of $\mathrm{N}$-acetylcysteine and hydration versus placebo and hydration in decreasing contrast-induced renal dysfunction in patients undergoing coronary angiography with or without concomitant percutaneous coronary intervention. Heart Lung 2007;36:195-204.

31. Shyu KG, Cheng JJ, Kuan P. Acetylcysteine protects against acute renal damage in patients with abnormal renal function undergoing a coronary procedure. J Am Coll Cardiol 2002;40:1383-8.

32. Webb JG, Pate GE, Humphries $\mathrm{KH}$, et al. A randomized controlled trial of intravenous $\mathrm{N}$-acetylcysteine for the prevention of contrastinduced nephropathy after cardiac catheterization: lack of effect. Am Heart J 2004;148:422-9.

33. Adolph E, Holdt-Lehmann B, Chatterjee T, et al. Renal Insufficiency Following Radiocontrast Exposure Trial (REINFORCE): a randomized comparison of sodium bicarbonate versus sodium chloride hydration for the prevention of contrast-induced nephropathy. Coron Artery Dis 2008;19:413-9. 
34. Motohiro M, Kamihata H, Tsujimoto S, et al. A new protocol using sodium bicarbonate for the prevention of contrast-induced nephropathy in patients undergoing coronary angiography. Am J Cardiol 2011;107:1604-8.

35. Tamura A, Goto Y, Miyamoto K, et al. Efficacy of single-bolus administration of sodium bicarbonate to prevent contrast-induced nephropathy in patients with mild renal insufficiency undergoing an elective coronary procedure. Am J Cardiol 2009;104:921-5.

36. Vasheghani-Farahani A, Sadigh G, Kassaian SE, et al. Sodium bicarbonate in preventing contrast nephropathy in patients at risk for volume overload: a randomized controlled trial. J Nephrol 2010;23:216-23.

37. Gomes VO, Lasevitch R, Lima VC, et al. Hydration with sodium bicarbonate does not prevent contrast nephropathy: a multicenter clinical trial. Arq Bras Cardiol 2012;99:1129-34.

38. Huber W, Schipek C, Ilgmann K, et al. Effectiveness of theophylline prophylaxis of renal impairment after coronary angiography in patients with chronic renal insufficiency. Am J Cardiol 2003;91:1157-62.

39. Matejka J, Varvarovsky I, Vojtisek P, et al. Prevention of contrastinduced acute kidney injury by theophylline in elderly patients with chronic kidney disease. Heart Vessels 2010;25:536-42.

40. Dvoršak B, Kanič V, Ekart R, et al. Ascorbic Acid for the prevention of contrast-induced nephropathy after coronary angiography in patients with chronic renal impairment: a randomized controlled trial. Ther Apher Dial 2013;17:384-90

41. Spargias K, Alexopoulos E, Kyrzopoulos S, et al. Ascorbic acid prevents contrast-mediated nephropathy in patients with renal dysfunction undergoing coronary angiography or intervention. Circulation 2004;110:2837-42.

42. Zhou L, Chen H. Prevention of contrast-induced nephropathy with ascorbic acid. Intern Med 2012;51:531-5.

43. Onbasili AO, Yeniceriglu Y, Agaoglu P, et al. Trimetazidine in the prevention of contrast-induced nephropathy after coronary procedures. Heart 2007;93:698-702.

44. Jo SH, Koo BK, Park JS, et al. Prevention of radiocontrast mediuminduced nephropathy using short-term high-dose simvastatin in patients with renal insufficiency undergoing coronary angiography (PROMISS) trial--a randomized controlled study. Am Heart $J$ 2008;155:499 e1-8.

45. Han Y, Zhu G, Han L, et al. Short-term rosuvastatin therapy for prevention of contrast-induced acute kidney injury in patients with diabetes and chronic kidney disease. J Am Coll Cardiol 2014;63:62-70.

46. Ko YG, Lee BK, Kang WC, et al. Preventive effect of pretreatment with intravenous nicorandil on contrast-induced nephropathy in patients with renal dysfunction undergoing coronary angiography (PRINCIPLE Study). Yonsei Med J 2013;54:957-64.

47. Jo SH, Kim SA, Kim HS, SH J, Kim HS, et al. Alpha-lipoic acid for the prevention of contrast-induced nephropathy in patients undergoing coronary angiography: the ALIVE study - a prospective randomized trial. Cardiology 2013;126:159-66.

48. Allaqaband S, Tumuluri R, Malik AM, et al. Prospective randomized study of $\mathrm{N}$-acetylcysteine, fenoldopam, and saline for prevention of radiocontrast-induced nephropathy. Catheter Cardiovasc Interv 2002;57:279-83.

49. Brueck M, Cengiz H, Hoeltgen R, et al. Usefulness of $\mathrm{N}$-acetylcysteine or ascorbic acid versus placebo to prevent contrast-induced acute kidney injury in patients undergoing elective cardiac catheterization: a single-center, prospective, randomized, double-blind, placebo-controlled trial. J Invasive Cardiol 2013;25:276-83

50. Castini D, Lucreziotti S, Bosotti L, et al. Prevention of contrastinduced nephropathy: a single center randomized study. Clin Cardio 2010;33:E63-E68.

51. Abizaid AS, Clark CE, Mintz GS, et al. Effects of dopamine and aminophylline on contrast-induced acute renal failure after coronary angioplasty in patients with preexisting renal insufficiency. Am J Cardiol 1999;83:260-3.

52. Geng W, Fu XH, Gu XS, et al. Preventive effects of anisodamine against contrast-induced nephropathy in type 2 diabetics with renal insufficiency undergoing coronary angiography or angioplasty. Chin Med J 2012;125:3368-72.

53. Baskurt M, Okcun B, Abaci O, et al. N-acetylcysteine versus $\mathrm{N}$-acetylcysteine + theophylline for the prevention of contras nephropathy. Eur J Clin Invest 2009;39:793-9.

54. Kimmel M, Butscheid M, Brenner S, et al. Improved estimation of glomerular filtration rate by serum cystatin $\mathrm{C}$ in preventing contrast induced nephropathy by $\mathrm{N}$-acetylcysteine or zinc--preliminary results. Nephrol Dial Transplant 2008;23:1241-5.
55. Ozcan EE, Guneri S, Akdeniz B, et al. Sodium bicarbonate, $\mathrm{N}$-acetylcysteine, and saline for prevention of radiocontrastinduced nephropathy. A comparison of 3 regimens for protecting contrast-induced nephropathy in patients undergoing coronary procedures. A single-center prospective controlled trial. Am Heart J 2007;154:539-44.

56. Saitoh $\mathrm{T}$, Satoh $\mathrm{H}$, Nobuhara $\mathrm{M}$, et al. Intravenous glutathione prevents renal oxidative stress after coronary angiography more effectively than oral N-acetylcysteine. Heart Vessels 2011;26:465-72.

57. Koc F, Ozdemir K, Kaya MG, et al. Intravenous N-acetylcysteine plus high-dose hydration versus high-dose hydration and standard hydration for the prevention of contrast-induced nephropathy: CASIS--a multicenter prospective controlled trial. Int J Cardiol 2012;155:418-23.

58. Gomes VO, Poli de Figueredo CE, Caramori P, et al. N-acetylcysteine does not prevent contrast induced nephropathy after cardiac catheterisation with an ionic low osmolality contrast medium: a multicentre clinical trial. Heart 2005;91:774-8.

59. Liu W, Ming Q, Shen J, et al. Trimetazidine Prevention of ContrastInduced Nephropathy in Coronary Angiography. Am J Med Sci 2015;350:398-402

60. Brar SS, Shen AY, Jorgensen MB, et al. Sodium bicarbonate vs sodium chloride for the prevention of contrast medium-induced nephropathy in patients undergoing coronary angiography: a randomized trial. JAMA 2008;300:1038.

61. Fan $Y$, Wei $Q$, Cai J, et al. Preventive effect of oral nicorandil on contrast-induced nephropathy in patients with renal insufficiency undergoing elective cardiac catheterization. Heart Vessels 2016;31:1776-82.

62. Weisbord SD, Gallagher $\mathrm{M}$, Jneid $\mathrm{H}$, et al. Outcomes after angiography with sodium bicarbonate and acetylcysteine. $N$ Engl $J$ Med 2018;378:603-14

63. JPT H. Cochrane Handbook for Systematic Reviews of Interventions. The Cochrane Collaboration, 2011.

64. Lewington A, MacTier R, Hoefield R, 2013. Prevention of Contrast Induced Acute Kidney Injury (Cl-AKI) In Adult Patients. Available from: http://www.rcr.ac.uk

65. Sun Z, Fu Q, Cao L, et al. Intravenous N-acetylcysteine for prevention of contrast-induced nephropathy: a meta-analysis of randomized, controlled trials. PLoS One 2013;8:e55124.

66. O'Sullivan S, Healy DA, Moloney MC, et al. The role of $\mathrm{N}-$ acetylcysteine in the prevention of contrast-induced nephropathy in patients undergoing peripheral angiography: a structured review and meta-analysis. Angiology 2013;64:576-82.

67. Trivedi H, Daram S, Szabo A, et al. High-dose N-acetylcysteine for the Prevention of Contrast-induced Nephropathy. Am J Med 2009;122:874.e9-e15

68. Kelly AM, Dwamena B, Cronin P, et al. Meta-analysis: effectiveness of drugs for preventing contrast-induced nephropathy. Ann Intern Med 2008;148:284-94

69. Gonzales DA, Norsworthy KJ, Kern SJ, et al. A meta-analysis of $\mathrm{N}$-acetylcysteine in contrast-induced nephrotoxicity: unsupervised clustering to resolve heterogeneity. BMC Med 2007;5:32.

70. Zagler A, Azadpour M, Mercado C, et al. N-acetylcysteine and contrast-induced nephropathy: a meta-analysis of 13 randomized trials. Am Heart J 2006;151:140-5.

71. Duong MH, MacKenzie TA, Malenka DJ. N-acetylcysteine prophylaxis significantly reduces the risk of radiocontrast-induced nephropathy: comprehensive meta-analysis. Catheter Cardiovasc Interv 2005;64:471-9.

72. Nallamothu BK, Shojania KG, Saint S, et al. Is acetylcysteine effective in preventing contrast-related nephropathy? A metaanalysis. Am J Med 2004;117:938-47.

73. Misra D, Leibowitz K, Gowda RM, et al. Role of N-acetylcysteine in prevention of contrast-induced nephropathy after cardiovascular procedures: a meta-analysis. Clin Cardiol 2004;27:607-10.

74. Bagshaw SM, Ghali WA. Acetylcysteine for prevention of contrastinduced nephropathy after intravascular angiography: a systematic review and meta-analysis. BMC Med 2004;2:38.

75. Isenbarger DW, Kent SM, O'Malley PG. Meta-analysis of randomized clinical trials on the usefulness of acetylcysteine for prevention of contrast nephropathy. Am J Cardiol 2003;92:1454-8.

76. Giacoppo D, Gargiulo G, Buccheri S, et al. Preventive Strategies for Contrast-Induced Acute Kidney Injury in Patients Undergoing Percutaneous Coronary Procedures: Evidence From a Hierarchical Bayesian Network Meta-Analysis of 124 Trials and 28240 Patients. Circ Cardiovasc Interv 2017;10:e004383.

77. Alonso A, Lau J, Jaber BL, et al. Prevention of radiocontrast nephropathy with $\mathrm{N}$-acetylcysteine in patients with chronic kidney disease: a meta-analysis of randomized, controlled trials. Am J Kidney Dis 2004;43:1-9. 
78. Birck R, Krzossok S, Markowetz F, et al. Acetylcysteine for prevention of contrast nephropathy: meta-analysis. Lancet 2003;362:598-603.

79. Heyman SN, Rosen S, Khamaisi M, et al. Reactive oxygen species and the pathogenesis of radiocontrast-induced nephropathy. Invest Radiol 2010;45:188-95.
80. Okamura DM, Pennathur S, Pasichnyk K, et al. CD36 regulates oxidative stress and inflammation in hypercholesterolemic CKD. J Am Soc Nephrol 2009;20:495-505

81. Andreucci M, Faga T, Pisani A, et al. Prevention of contrast-induced nephropathy through a knowledge of its pathogenesis and risk factors. ScientificWorldJournal 2014;2014:1-16. 